\title{
Prospective Studies on Pattern of Two Wheeler Injuries in Road Traffic Accidents
}

\author{
Arun Prakash K.S. ${ }^{1}$, Sanjeev K. ${ }^{2}$, Gambhir Singh O. ${ }^{3}$ \\ ${ }^{1}$ Assistant Professor, ${ }^{2}$ Associate Professor, ${ }^{3}$ Professor \& HOD, Department of Forensic Medicine, \\ SRM Medical College Hospital and Research Centre, Kattankulathur, Chennai-603 203
}

\begin{abstract}
It is a prospective study of fatal two wheelers accident cases brought at Indira Gandhi Government General Hospital \& Post Graduate Institute, Puducherry. Amongst 118 cases, $79.66 \%$ were male whereas $20.33 \%$ were female. Highest numbers of victims were in the age group of 36-55 years, accounting for 45 (38.13\%). There was a higher rate of head and neck injuries in the present study followed by head, neck \& lower limb and head, neck \& upper limb. Numbers of people who succumb to two wheeler accidents are on an increasing trend in India. Fatality rates among the people involved in RTA shows an alarming increase. It was observed that violating the traffic rules is found to be the major contributory factor and men and teenagers are the most common people involved in these accidents. Measures to prevent these accidents and decrease the mortality rates in these situations includes strict adherence to traffic rules.
\end{abstract}

Keywords: Two wheelers, Road Traffic Accidents, Drunken Drive, Mechanical injuries.

\section{Introduction}

Road traffic accidents are the only public health problem for which society and decision makers still accept death and disability among young people on a large scale ${ }^{1}$. India ranks 1 st in the number of road accident deaths among 199 countries reported in the World Road Statistics, 2018 followed by China and the US. As per the WHO Global Report on Road Safety 2018 , India accounts for almost $11 \%$ of the accidentrelated deaths in the World ${ }^{2}$.

According to the National Crime Records Bureau (2010), the number of vehicular accidents was 430600 resulting in 133938 deaths and 470600 injuries, thereby accounting for $37.2 \%$ of all accidental deaths (3). A

\section{Corresponding Author:}

\section{Dr. Arun Ks Prakash MD., LL.B.}

Assistant Professor, Department of Forensic Medicine, SRM Medical College Hospital and Research Centre, Kattankulathur-603 203

Mobile Number: 9842292308

e-mail: drarunksprakash@gmail.com study was conducted for five years form 2000 -2004 to draw the pattern between the age, sex of the victim, type of injury, and their association with the road traffic accidents. As per the results a majority of $77 \%$ were in the age group from 18-44 years accounted for nearly 69.6 percent of road accident victims, the accident ratio was $83 \%$ in male whereas for the female it was $17 \%$. They have also mentioned that $81 \%$ of the geared vehicles have been a part of the accidents that occurred (4). Tamil Nadu and Uttar Pradesh accounted for the highest number of road accidents and death in road accidents respectively in 2018, the report revealed (2).

Because, most of the national highways in India are made by tar and the fact is that the national highway is 24 hrs busiest roads with vehicles travelling at high speeds, the roads being less wider multiple intersections and divider cuts are present at every kilometre for changing the side. ${ }^{3,4,5}$.

Though the facts of the motorcycle accidents are obvious no much attention is paid to it. The accidents by a motorbike is 27 times fatal than a caras by the source ${ }^{5}$. This does not imply that car accidents are less damaging but the impact and the numbers are greater on the comparison. 


\section{Method and Materials}

The study is a prospective analysis of cases of fatal two wheelers accident autopsied at Indira Gandhi Government General Hospital \& Post Graduate Institute, Puducherry during the period November 2013 through April 2015 after obtaining ethical clearance. Out of the total 159 cases of RTA we have chosen 118 cases where two wheelers were involved. External and internal postpartum findings were observed and recorded in the performa. History about the accident, the time, day, month, type of road, type of vehicle, were obtained from investigating officer and relatives of the deceased and were recorded in the Performa. The cases with incomplete details were not taken into consideration.

The data were analyzed with SPSS-20 software and the results were interpreted in terms of percentage, mean, chi-square, and z-test. Then we compared our findings with the works of other authors.

Observation: There were 118 fatal two wheelers accident cases out of the total 159 fatal road traffic accident dead cases. Age-wise, Sex-wise and other findings are displayed in Table No.1. Amongst 118 patients, $79.66 \%$ were male whereas $20.33 \%$ were female. Highest numbers of victims were in the age group of 36-55 years, accounting for 45 (38.13\%) patients. On applying, Chi-square test, it is shown that the age group 36-55 years and above 55 years is statistically significant. Male are more vulnerable to two wheeler accidents than female. $98.30 \%$ of the patients got accident in Tar road than cement \& Mud road.

Table No. 1: Age-Sex-Type of Road Involved

\begin{tabular}{|l|c|c|c|c|c|c|}
\hline \multirow{2}{*}{$\begin{array}{l}\text { Age Group } \\
\text { (Years) }\end{array}$} & \multirow{2}{*}{ Total } & \multicolumn{2}{|c|}{ Sex } & \multicolumn{3}{c|}{ Type of Road } \\
\cline { 3 - 7 } & & Male & Female & Tar Road & Cement Road & Mud Road \\
\hline $1-18$ Years & $4(3.38 \%)$ & $4(3.38 \%)$ & 0 & $3(2.54 \%)$ & $1(0.84 \%)$ & 0 \\
\hline 19-35 Years & $31(26.27 \%)$ & $25(21.18 \%)$ & $6(5.08 \%)$ & $30(25.42 \%)$ & 0 & $1(0.84 \%)$ \\
\hline $36-55$ years & $45(38.13 \%) *$ & $35(29.66 \%)$ & $10(8.47 \%)$ & $45(38.13 \%)$ & 0 & 0 \\
\hline Above 55 years & $38(32.20 \%) *$ & $30(25.42 \%)$ & $8(6.77 \%)$ & $38(32.20 \%)$ & 0 & 0 \\
\hline Total & $\mathbf{1 1 8 ( 1 0 0 \% )}$ & $\mathbf{9 4 ( 7 9 . 6 6 \% )}$ & $\mathbf{2 4 ( 2 0 . 3 3 \% )}$ & $\mathbf{1 1 6 ( 9 8 . 3 0 \% )}$ & $\mathbf{1 ( 0 . 8 4 \% )}$ & $\mathbf{1 ( 0 . 8 4 \% )}$ \\
\hline
\end{tabular}

*Indicates $\mathrm{P}<0.01$, that is significant

Table No. 2 shows distribution of cases according to manner of accident. In 36 cases, $(36.50 \%)$ it was due to hitting against the pedestrian. In 25 cases, (21.23\%) death were by collision with heavy passenger vehicle.

Table No. 2: Distribution of Cases According to Manner of Collision

\begin{tabular}{|l|c|c|}
\hline History of Accident & Frequency & Percentage \\
\hline 2 wheeler hitting against the fixed object & 12 & $10.16 \%$ \\
\hline Fall from 2 wheeler & 20 & $16.94 \%$ \\
\hline 2 wheeler hitting against the pedestrian & 36 & $30.50 \%$ \\
\hline 2 wheeler vs 2 wheeler & 9 & $7.62 \%$ \\
\hline 2 wheeler vs Heavy passenger vehicle & 14 & $11.86 \%$ \\
\hline 2 wheeler vs Bicycle & 4 & $3.38 \%$ \\
\hline 2 wheeler vs Heavy vehicle & 11 & $9.32 \%$ \\
\hline 2 wheeler vs 4 wheeler & 12 & $10.16 \%$ \\
\hline Total & $\mathbf{1 1 8}$ & $\mathbf{1 0 0 \%}$ \\
\hline
\end{tabular}


Analysis of various injuries in the body of the victims revealed that the maximum number of patients got injured in the head \& neckregion $(25.42 \%)$ shown in Table No.3. Head \& Neck and upper limb (9.32\%), head \& Neck and lower limb (11.01\%), Head \& neck and thorax (7.62\%), head \& Neck and upper limb (8.47\%), Head \& neck, abdomen and upper limb (8.47\%), head \& neck, abdomen and lower limb (10.16\%), head \& neck, thorax, pelvis and lower limb (6.77\%), Head \& Neck, Abdomen, Groin, Spine and Back (9.32\%) and Head \& Neck, Abdomen, Groin, Spine, Lower limb and Back $(11.86 \%)$ were more predominantly injured area in the accident.

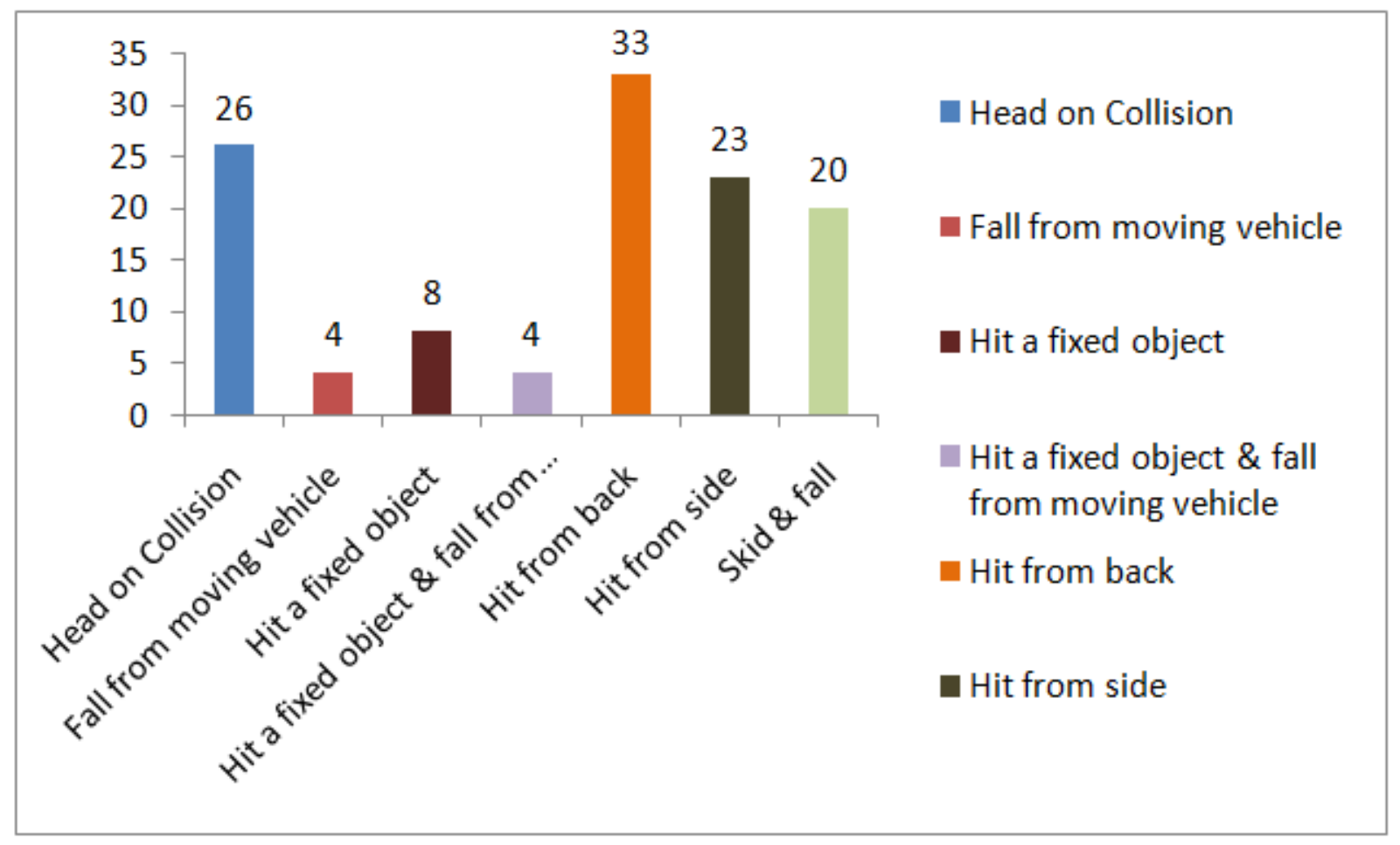

Figure 1: Bar Chart shows the distribution of type of accidents

Table No. 3: Distribution of Injured Body Surface

\begin{tabular}{|l|c|c|}
\hline Site of Injury & Frequency & Percentage \\
\hline Head \& Neck & 30 & $25.42 \%$ \\
\hline Head \& Neck and Upper limb & 11 & $9.32 \%$ \\
\hline Head \& Neck and Lower limb & 13 & $11.01 \%$ \\
\hline Head \& Neck and Thorax & 9 & $7.62 \%$ \\
\hline Head \& Neck, Abdomen and Upper limb & 10 & $8.47 \%$ \\
\hline Head \& Neck, Abdomen and Lower limb & 12 & $10.16 \%$ \\
\hline Head \& Neck, Thorax, Pelvis and Lower limb & 8 & $6.77 \%$ \\
\hline Head \& Neck, Abdomen, Groin, Spine and Back & 11 & $9.32 \%$ \\
\hline Head \& Neck, Abdomen, Groin, Spine, Lower limb and Back & 14 & $11.86 \%$ \\
\hline Total & $\mathbf{1 1 8}$ & $\mathbf{1 0 0 \%}$ \\
\hline
\end{tabular}

Most common injuries observed were abrasion, laceration, sutured wound and contusion observed in all 118 cases. In that combination of abrasion \& laceration (26.27\%) is the most common type of injuries observed in the patients and followed by Abrasion, Abrasion \& Sutured wound, Abrasion, Laceration, Sutured wound \& Contusion were $19.49 \%, 16.94 \%, 14.40 \%$ respectively shown in Table No. 4. 
Table No. 4: Cases Distribution According to Injury Type

\begin{tabular}{|l|c|c|}
\hline Type of Injury & Frequency & Percentage \\
\hline Contusion & 6 & $5.08 \%$ \\
\hline Abrasion & 23 & $19.49 \%$ \\
\hline Laceration & 14 & $11.86 \%$ \\
\hline Abrasion \& Contusion & 7 & $5.93 \%$ \\
\hline Abrasion \& Laceration & 31 & $26.27 \%$ \\
\hline Abrasion \& Sutured wound & 20 & $16.94 \%$ \\
\hline $\begin{array}{l}\text { Abrasion, Laceration, Sutured } \\
\text { wound \& Contusion }\end{array}$ & 17 & $14.40 \%$ \\
\hline Total & $\mathbf{1 1 8}$ & $\mathbf{1 0 0 \%}$ \\
\hline
\end{tabular}

As shown in figure 2, the injuries were commonly seen on the the face \& lower limb 27(22.88\%), followed by cerebral Lobes $(21.18 \%)$, lobes, upper limb, lower limb \& face (16.94\%), cerebral lobes \& lower limb (16.10\%), upper limb \& lower limb (16.10\%). The less common area are lobes \& upper limb (6.77\%).

\section{Discussion}

Road traffic accidents are more common in a developing country like India. In this study, the majority of motor cyclist and pillion riders were adultsand in their most productive ages and showed a male preponderance. Present study is in consistent with the works of other authors ${ }^{1.2,3,4}$.

The results of the present study revealed that 94 $(79.66 \%)$ of the patients were males and the rest 24 $(20.33 \%)$ were females. The highest number of patients 45 (38.13\%) were from 36-55 years of age group. Among males, the maximum numberof cases were seen in the age group of 36-55 years $35(29.66 \%)$ and above 55 years $30(25.42 \%)$. The mean age of the RTA victim came out to be 30.12 yrs. However, other studies observed that mean age of the male victimized in road traffic accidents is 33 years. ${ }^{6-11}$.

Due to high activity levels, participation in high-risk activities, reckless driving/riding, over-speeding and drunken driving, driving without wearing helmetsetc are main reason for high incidence rate among males. Similar observations were also reported by different authors $^{6-9}$. On the other hand females due to social \& cultural practice are less expose to road traffic accidents. Moreover, extra precautions taken by family members to keep them safe women have lesser possible to encounter road traffic accidents than male partners. Majority of these accidents occurred on the paved roads 116 $(98.30 \%)$.

There was a higher rate of head and neck injuries in the present study followed by head, neck \& lower limb and head, neck \& upper limb. A possible explanation might be that two wheeler inhabitants did not use seat belts, resulting in forward jerk during a collision and higher rate of injury. Abrasions, lacerations, sutured wound and contusion were the commonest types of injuries among the external injuries noted in this study. Similar results were also observed by others researchers ${ }^{12-16)}$. Common sites for injuries were the lower and upper limbs and face $^{6,7}$.

Face \& lower limb injury is more frequent in motor vehicle occupant 27(22.88\%) followed by Lobes (21.18\%), lobes, upper limb, lower limb \& face (16.94\%), lobes \& lower limb (16.10\%), upper limb \& lower limb $(16.10 \%)$. The less common area are lobes \& upper limb $(6.77 \%)$. It therefore, appears that motor vehicle occupant and motor cyclist were more vulnerable to the different type of injuries than other categories of the victims possibly due to a greater force of impact in the former and a longer distance of the fall in the latter ${ }^{16,17}$ whereas the study conducted by Clark DW reported that more number of fractures appeared in the area of upper limbs, lower limbs and facial bones ${ }^{18}$. In line with our study Wong TW showed that commonest injury was fracture of bones particularly of the head and face and closely followed by the lower extremity ${ }^{18,19}$.

\section{Conclusion}

The study highlights the pattern of injuries among the motor cyclists. By analyzing the various data that were published on RTAs and their major contributing factors, accidents are happening usually due to irresponsibility of the rivers. Hence, we recommend strict enforcement of the traffic rules and safety law for the motor cyclist like wearing the helmet, maintaining the speed limit etc. Moreover, advancement in technology of the wheelers has brought great advantages to the human but on the other hand the mishandling of these two-wheelers can even cause fatal death or injury. India has recorded the maximum number of deaths in two-wheeler accidents with a greater ratio of men being affected than the women because of not following the traffic laws Understanding the speed limit and obeying traffic laws could reduce the number of people affected by the accidents. It is high time that the policy makers should take a look at these 
types of studies and do concerned modifications in the years to come.

Ethical Clearance is taken from Departmental Research Committee to Amity Law School, Amity University, Noida, U.P.

Source of Funding: Self

Conflict of Interest: Nil

\section{References}

1. Mohan D. Road traffic injuries-a neglected pandemic. Bulletin World Health Organisation 2003; 81(9):684-5

2. The Economic Times. Road Accidents Claimed over 1.5 lakhs in 2018. 2018

3. National Crime Record Bureau. Annual Report on Road Accidents. 2010

4. Jain A, Manazes RG, Kanchan T, Gagan S. Two wheeler accidents on Indian roads - a study from Mangalore. J Forensic and Legal Medicine. 2009; 16(3): 130-3.

5. Dolman Law Group. Five facts you should know about motor cycle accidents. 2018

6. Mehta SP. An epidemiological study of road traffic accident cases admitted in Safdarjang Hospital, New Delhi. Indian J Med Res. 1968;56:456-66.

7. Sathiyasekaran BW. Study of the injured and the pattern in road traffic accidents. Indian J Forensic Sci. 1991;5:63-8.

8. Ghosh PK. Epidemiological study of the victims of vehicular accidents in Delhi. J Indian Med Assoc. 1992;90:309-12.

9. Varghese M, Mohan D. New Delhi: Proceedings of the International Conference on Traffic Safety; 1991. Jan 27-30, Transportation injuries in rural Haryana, North India 1991.
10. Clark DW, Morton JH. The motorcycle accident: A growing problem. J Trauma. 1971;11:230-7.

11. Akang EE, Kuti MA, Osunkoya AO, Komolafe EO, Malomo AO, Shokunbi MT, et al. Pattern of fatal head injuries in Ibadan - A 10 year review. Med Sci Law. 2002;42:160-6.

12. Kual A, Sinha US, Pathak YK, Singh A, Kapoor AK, Sharma S, et al. Fatal road traffic accidents, study of distribution, nature and type of injury. J Indian Acad Forensic Med. 2005;27:71-6.

13. Dhillon S, Kapila P, Sekhon HS. Pattern of injuries in road traffic accidents in Shimla hills. J Punjab Acad Forensic Med Toxicol. 2007;7:50-3.

14. Kumar PM, Ziya A, Prashant A, Yadav S, Chaturvedi R, Tripathi SK. Fatality due to chest injury in Road traffic accident victims of Varanasi and adjoining districts, U.P. Medico-Legal Update. 2006;6:7-9.

15. Singh H, Dhattarwal SK. Pattern and distribution of injuries in fatal road traffic accidents in Rohtak (Haryana) J Indian Acad Forensic Med. 2004;26:20-3.

16. Sharma BR, Harish D, Singh G, Vijay K. Patterns a Head Injury in Road Traffic Accidents, Bahrain Medical Bulletin 2003;25(1):22-25. 12.

17. Kumar S, Suresh B, Kanchan T, Ritesh G, Shankar M, Bakkannavar, Vinod C, Nayak K, Yoganarasimha. Victim Profile and Pattern of Thoraco-Abdominal Injuries Sustained in Fatal Road Traffic Accident. JIAFM 2012; 34(1):16-19

18. Clark DW, Morton JH. The motorcycle accident: A growing problem. J Trauma. 1971;11:230-7

19. Wong TW, Phoon WO, Lee J, Yiu PC, Fung KP, Smith G, et al. Non-fatal injuries among motorcyclists treated as in-patients in a general hospital. Ann Acad Med Singapore. 1989; 18:672-4. 